\title{
Corrosion behavior of the high strength low alloy steel joined by vertical electro-gas welding and submerged arc welding methods
}

\author{
Weiming Liu ${ }^{\text {a, }}$ Hongbo Pan Liaosha Li Huihong Lv Zhaojin Wu Fabin Cao Jianhua Zhu \\ Key Laboratory of Metallurgical Emission Reduction \& Resources Recycling, Ministry of \\ Education Anhui University of technology, Maanshan 243002 P.R.China
}

\begin{abstract}
The high strength low alloy (HSLA) steel used as a large crude oil storage tank (LCOST) was often welded by vertical electro-gas welding (VEGW) and submerged arc welding (SAW). The VEGW specimen was produced by single-pass weld with high heat input (about $100 \mathrm{KJ} / \mathrm{cm}$ ), and the SAW specimen was manufactured by mutil-pass weld with low heat input (about $30 \mathrm{KJ} / \mathrm{cm}$ ). The corrosion behaviors of both samples were studied by electrochemical techniques and surface methods. The research results achieved in this investigation disclosed that the welding process played an important role in obtaining satisfactory corrosion property. In comparison with the SAW joint, the VEGW joint showed uniform microstructure and coarse micro-phase. The scanning vibrating electrode technique (SVET) results demonstrated that the corrosion of the VEGW joint majorly took in the heat effect zone (HAZ) and the attack for the SAW joint mainly occurred in the fusion zone (FZ). In addition, the scanning electron microscopy (SEM) results exhibited that the VEGW joint exhibited a light local attack and the SAW joint demonstrated a

*Corresponding author. Tel.: +86 05552311879 fax: +86 05552311879.

E-mail address:liuweiming1979@126.com (Weiming Liu).
\end{abstract}


heavy uniform corrosion. The electrochemical results showed that the VEGW joint showed lower corrosion rate than the SAW joint. In summary, it can be discovered that the corrosion rates of welded specimens were associated with the welding-pass and the corrosion forms of welded specimens were related to the heat input energy.

Key words: vertical electro-gas welding; submerged arc welding; corrosion behavior; electrochemical impedance spectra; scanning vibrating electrode technique; heat effect zone

\section{Introduction}

The high strength low alloy (HSLA) steel has been widely used to build a large crude oil storage tank (LCOST) [1]. During build process, The horizontal welding seam is produced by submerged arc welding( SAW) and the vertical welding seam is joined by vertical electro-gas welding (VEGW)[2]。 The LCOST steel has been produced in the major steel enterprise Baosteel, WISCO, Ansteel and Shougang. The Welded joints of the LCOST steel exhibit good mechanical property and excellent welding ability, however, the corrosion problems caused by chloride have been paid more and more attention on the LCOST by now. This is due to that the domestic crude oil comes from the ocean and makes the seawater as pressure water during exploitation. In addition, the import crude oil mostly comes from the Middle East and contains many chlorides [3]. As a result, the corrosion of crude oil becomes more and more serious, which takes serious corrosion to the LCOST and shortens its service life. Therefore great economic losses are caused by the corrosion of the LCOST. On the other hand, seawater is seemed to substitute to freshwater in 
hydraulic experiment during the LCOST building, which can save lots of freshwater resources and construction costs. However, seawater can lead to serious corrosion for the LCOST by the chloride. Therefore, it is necessary to study corrosion problems for the LCOST in chloride solution, especially to the welding joint site for the most sensitive corrosion in the LCOST.

It was proposed that the welding would increase the corrosion activity of the HSLA steel due to metallurgical changes and residual stresses introduce a series of phase transformations taking place in the fusion zone (FZ) and heat effect zone (HAZ), In recent years, there have been many researches on the mechanical property and welding ability for the welded joint of the LCOST steel [4-6], however, there were few researches on its corrosion behaviors [7]. As a result, it is necessary to study the corrosion behaviors of welded joints of the LCOST steel in $3.5 \% \mathrm{NaCl}$ solution.

In this work, scanning vibrating electrode technique (SVET) combined with scanning electron microscopy (SEM) observation as well as electrochemical impedance spectroscopy (EIS) measurement, was used to investigate the corrosion behaviors of welding joints of the LCOST steel in $3.5 \% \mathrm{NaCl}$ solution.

\section{Experimental procedures}

\subsection{Sample preparation}

Test specimens were cut from the longitudinally welded LCOST steel containing welded metal (WM), HAZ and base metal (BM). The chemical compositions of the LCOST steel and filler metal were shown in Table 1. 
Butt welds were made on plates of $250 \mathrm{~mm} \times 200 \mathrm{~mm} \times 32 \mathrm{~mm}$ using VEGW and SAW. The size of welding groove was shown in Fig.1.The VEGW joint was made using by single-pass welding and established suitably welding parameters (i.e., $450 \mathrm{~A}$ welding current, $45 \mathrm{~V}$ welding voltage, $12 \mathrm{~cm} / \mathrm{min}$ welding speed, $100 \mathrm{KJ} / \mathrm{cm}$ heat input). The SAW joint was produced by multi-pass welding and optimally welding parameters (produced using welding current of $500 \mathrm{~A}$, welding voltage of $30 \mathrm{~V}$, welding speed of $40 \mathrm{~cm} / \mathrm{min}$, heat input of $30 \mathrm{KJ} / \mathrm{cm}$ and argon shielding flow rate of 15 L/min welding parameters). Radiographic (RT) examined all welded joints showed that they were full penetration and acceptable bead profile with no welding defects such as porosity, undercut, cracks, or lack of fusion. Cross-section micro-images of both welding technology were shown in Fig.2, which exhibited that both of these joints had good welded quality. Welded samples were machined by electrochemical sample with $10 \mathrm{~mm} \times 10 \mathrm{~mm} \times 10 \mathrm{~mm}$. All sides of the specimen were embedded in an epoxy resin except the exposure surface, which was ground sequentially with 400 , 600, and 800 grit emery papers. The specimen was cleaned by distilled water and degreased in acetone. Finally, a specimen was subjected for $5 \mathrm{~min}$ to ultrasonic washing with acetone and dried in warm flowing air prior to every experiment. EIS began after a $2 \mathrm{~h}$ immersion for samples to reach a steady state condition.

\subsection{Experimental device description}

Both electrochemical measurements were performed in a standard three-electrochemical cell, with a saturated calomel electrode (SCE) as the reference electrode, a platinum sheet as the auxiliary electrode (AE), and the samples as the 
working electrode (WE). Polarization curve and EIS were carried out in a VMP3 electrochemical corrosion testing apparatus at room temperature in $3.5 \% \mathrm{NaCl}$ solution. For the potentiodyanmic curve, the sweeping potential was from $-0.25 \mathrm{~V}$ to $0.25 \mathrm{~V}$ with a scanning rate of $0.1667 \mathrm{mV} / \mathrm{s}$. EIS measurements were performed at the open circuit potential with $\mathrm{AC}$ amplitude of $5 \mathrm{mV}$, and the applied frequencies ranged from $0.01 \mathrm{~Hz}$ to $10 \mathrm{KHz}$. At least three tests were conducted under each condition to confirm the validity of the experiment measurements.

The SVET measurements were conducted through a PAR370 Scanning Electrochemical Workstation. The detailed setup was described as previous works [8]. A video camera was used for imaging and controlling the distance between the Pt-Ir micro-probe and the work electrode surface, which was set at $100 \mu \mathrm{m}$. The vibrating amplitude of the micro-electrode was $25 \mu \mathrm{m}$ and the vibrating frequency was $400 \mathrm{~Hz}$ in the direction to the surface. The potential of the microelectrode was proportional to its position in the vibrating plane. The difference of the potentials when the microelectrode was located at the vibrating peak and valley, respectively, $\triangle E$, was measured by an electrometer incorporated in M370. The solution resistance between the vibrating peak and valley, $R$ is determined by $R=d / k$, where $d$ is the vibrating amplitude of the microelectrode $(35 \mu \mathrm{m})$ and $k$ is the solution conductivity. The SVET current $I$ was then obtained by $I=\triangle E / R$ polishing with diamond paste, and etched by a mixture of $5 \%$ nitric acid and ethanol.

Micro-hardness test was conducted through a nano-indentation measuring device (TI900 Tribo-Indenter, Hysteron). In a force-controlled mode, the indenter tip 
(Berovich type triangular pyramid) was loaded with a peak force of $3000 \mu \mathrm{N}$ at a rate of $50 \mu \mathrm{N} / \mathrm{s}$.

Scanning electrode microscopy (SEM) was utilized to investigate the corrosion morphologies of removed corrosion scales for the SAW joint and the VEGW joint after $144 \mathrm{~h}$ of immersion in $3.5 \% \mathrm{NaCl}$ solution.

\section{Result and discussion}

\subsection{Microstructure of SAW and VEGW welds}

Fig. 3 shows the micrographs for the VEGW samples of WM, HAZ and BM, respectively. Various micro-phases are observed in different zones. The BM is character to bainite and acicular ferrite. The WM is featured with allotriomorphic ferrite, acicular ferrite and tempered bainite. The HAZ contains incomplete heat affected zone (ICHAZ), fine grain heat affected zone (FGHAZ) and coarse grain heat affected zone (CGHAZ), as shown in Fig3b( I), Fig3b( II ) and Fig3b( III), respectively. The CGHAZ adjacented to the fusion line could be resulted from nearly complete austenite dissolution on heating and subsequent ferrite grain growth. The microstructure of CGHAZ is polygonal ferrite and pearlite. The micro-phase of FGHAZ is fine polygonal ferrite, pearlite and acicular ferrite, while the micro-phase of ICHAZ is featured with acicular ferrite and granular bainite.

Fig. 4 shows optical micrographs of the cross section of the different welding regions (BM, HAZ and $\mathrm{WM}$ ) of the SAW joint. The different zone in the HAZ is demonstrated in Fig. 4b, which contains ICHAZ( Fig4b( I )), FGHAZ(Fig4b( II )) and CGHAZ (Fig4b(III)), respectively. The microstructure of CGHAZ consists of stripped 
ferrite with tempered bainite. The micro-phase of FGHAZ is the mixture phase of pearlite and nubble ferrite. The micro-phase of ICHAZ is featured with acicular ferrite and granular bainite. The WM microstructure consists of pearlite and polygonal ferrite. Compare with the VEGA joint, the SAW joint shows finer micro-phase in welding zone, which is relate to the high heat input by the VEGW technology.

Typical microhardness profiles of welding samples are shown in Fig. 5. It can be shown that the hardness values of the VEGW joint are symmetric distribution as a centre of the FZ. The micro-hardness of the BM is about $230 \mathrm{HV}$. WM and HAZ show little lower micro-hardness values, $190 \mathrm{HV}$ for WM and 165 185 HV for HAZ. It can be concluded that the VEGW joint shows relatively the uniform fluctuations of micro-hardness in welding zone (WZ). Generally, the micro-hardness profiles of the SAW joint reveal that the micro-hardness values gradually decrease along the welding direction, which is related to mutil-pass welding technology [9]. The micro-harness values of the SAW joint are 205 235 HV for WM and 195 245 HV for HAZ. It can be confirmed that the SAW joint exhibits more obvious micro-hardness fluctuate in welding zone than the VEGW joint, which is due to the mutil-pass weld for the SAW joint that makes the welding zone suffering many times metallurgical change and making worse microstructure uniformity. Thus, it is indicate that the microstructure homogeneity of VEGW is better than that of SAW.

\subsection{Corroded surface characterization}

Fig.6 shows corrosion morphologies of welding samples in $3.5 \% \mathrm{NaCl}$ solution after 144 hours. It can be shown in Fig. 6(a) that the VEGW joint exhibits obvious 
local corrosion in the welding zone and light corrosion in whole welding joint, which is related to the microstructure characteristics of welding samples. For the VEGW joint, it can be observed many coarse micro-phases in welding zone in Fig. 3, and it can be revealed symmetrical micro-hardness fluctuation in welding joint in Fig.5. Thus, the VEGW joint exhibits a light local corrosion in $3.5 \% \mathrm{NaCl}$ solution. The SAW joint presents a heavy corrosion uniform attack in Fig 6(b), which is related to the homogeneity of the microstructure. It can be shown in Fig 5 that the SAW joint shows obvious hardness fluctuation in welded zone, which reveals the inhomogeous microstructure of the SAW joint. This leads to heavy corrosion for the SAW joint in $3.5 \% \mathrm{NaCl}$ solution.

\subsection{SVET measurement}

SVET is a new technique, which can measure the local corrosion potential under untouched sample surface. The electrochemical reaction took place on the active surface of the welded specimen in $3.5 \% \mathrm{NaCl}$ solution. The ion current could flow during reaction process and lead to the small change of corrosion potential. SVET can measure this small change of the corrosion potential. Fig 7 shows the SVET maps to measure on the welding specimen after $1 \mathrm{~h}$ of immersion in $3.5 \% \mathrm{NaCl}$ solution. Fig 7(a) reveals that, for the VEGW joint, corrosion currents of BM show lower than those of HAZ and WM, thus BM exhibits a local cathode zone and forms local form on the sample surface ( in Fig 6(a)). The distribution of the corrosion currents shows a relatively uniform distribution in BM. There is a maximum dissolution current density up to $3.85 \times 10^{-4} \mathrm{~A} / \mathrm{mm}^{2}$ in the $\mathrm{HAZ}$ adjacent to the $\mathrm{BM}$ and the smallest current 
density of about $1.9 \times 10^{-4} \mathrm{~A} / \mathrm{mm}^{2}$ in the BM. As shown in Fig 7(b), it can be seem that the SAW joint exhibits worse homogeneous distribution and higher corrosion current in the WM and the HAZ. As a result, the SAW joint exhibits heavy corrosion in Fig.6(b). A maximum dissolution current density is up to $4.5 \times 10^{-4} \mathrm{~A} / \mathrm{mm}^{2}$ in the WM adjacent to the HAZ, and the minimum current density of about $2.1 \times 10^{-4} \mathrm{~A} / \mathrm{mm}^{2}$ in the BM. Compared with the VEGW joint, It can be indicate that the SAW joint show higher corrosion current than the VEGW joint in $3.5 \% \mathrm{NaCl}$ solution, which is fit to the SEM results.

\subsection{Polarization curve}

Fig 8 shows the potentiostatic polarization for the WM, HAZ and BM of welding samples after $1 \mathrm{~h}$ in $3.5 \% \mathrm{NaCl}$ solution. It can be shown that both of these welding samples show similar corrosion behaviors. Anodic current densities continuously increase with an increase in corrosion potentials, which indicates that all samples display an active dissolution behavior in $3.5 \% \mathrm{NaCl}$ solution.

Table 2 shows corrosion potentials $\left(E_{\text {corr }}\right)$, polarization resistances $\left(R_{\mathrm{p}}\right)$, Tafel slopes ( $b_{\mathrm{a}}$ and $b_{\mathrm{c}}$, anodic and cathodic, respectively) and corrosion currents $\left(I_{\mathrm{corr}}\right)$ simulated by the polarization curve results. As shown in Table 2 for the VEGA joint, It can be observed that HAZ has a more negative potential $\left(-530 \mathrm{mV}_{\mathrm{SCE}}\right)$ than $\mathrm{WM}(-513.29$ $\left.\mathrm{mV}_{\mathrm{SCE}}\right)$ and $\mathrm{BM}\left(-470 \mathrm{mV}_{\mathrm{SCE}}\right)$, which means that its $\mathrm{HAZ}$ shows an obvious electrochemical reaction activity. At a meantime, the corrosion current density of BM is $16.80 \mu \mathrm{A} \mathrm{cm}^{-2}$, which is close to $\mathrm{WM}\left(18.77 \mu \mathrm{A} \mathrm{cm}^{-2}\right)$, and lower than that of HAZ $\left(21.39 \mu \mathrm{A} \mathrm{cm}^{-2}\right)$. It can be shown that there is a high dissolution current density at 
HAZ, which is in accordance with the SEVT result. For the SAW joint, WM shows the most negative corrosion potential $\left(-789.1 \mathrm{mV}_{\mathrm{SCE}}\right)$ than $\mathrm{HAZ}\left(-604.6 \mathrm{mV}_{\mathrm{SCE}}\right)$ and $\mathrm{BM}\left(-472.2 \mathrm{mV}_{\mathrm{SCE}}\right)$, which imply that its $\mathrm{WM}$ is prone to attack in $3.5 \% \mathrm{NaCl}$ solution. Furthermore, the corrosion current of $\mathrm{WM}$ is $23.07 \mu \mathrm{A} \mathrm{cm} \mathrm{cm}^{-2}$, which is obviously more than those of $\operatorname{HAZ}\left(19.9 \mu \mathrm{A} \mathrm{cm} \mathrm{cm}^{-2}\right)$ and $\mathrm{BM}\left(17.10 \mu \mathrm{A} \mathrm{cm} \mathrm{cm}^{-2}\right)$. The results show the WM of SAW joint exhibits higher corrosion rate than the others in $3.5 \% \mathrm{NaCl}$ solution.

The corrosion behaviors of both joints are listed in Table 2. It can be discovered that the SAW joint exhibits more positive corrosion potentials and higher corrosion currents than the VEGW joint, which means the SAW joint manifests lower corrosion tendency and higher corrosion rate in $3.5 \% \mathrm{NaCl}$ solution, which agrees with the SEM result.

\subsection{EIS measurement}

The key aim of the EIS experiment is to provide insight into the characteristics and kinetics of the electrochemical process occurring at the interface of Fe/solution in $3.5 \% \mathrm{NaCl}$ solution. The working electrodes had been immersed in $3.5 \% \mathrm{NaCl}$ solution until the formation of a stable state. Fig. 9 illustrates the typical Nyquist diagrams of welding samples obtained at different immersion time. all samples exhibit similar corrosion behaviors during corrosion process, and the Nyquist plots show increasing capacitance arcs with the increasing time in Figs. 9(a) and 9(b), indicating an activation-like behavior. With an increase in the immersion time, EIS shows two capacitance arcs in Figs. 9(c) and 9(d), and a new capacitance arc is related to the 
formation of the local corrosion on sample surface.

According to EIS results in Fig. 9, the equivalent circuits are illustrated in Fig. 10. Fig. 10a is fitted to the impedance spectra with one-time constant. Fig. 10b is simulated to the impedance spectra with two time constants. In these models, $R_{\mathrm{s}}$ is the solution resistance, $\mathrm{CPE}_{\mathrm{pit}}$ and $R_{\mathrm{pit}}$ correspond to the local corrosion capacitance and resistance, respectively. $R_{\mathrm{ct}}$ is the reaction resistance. $\mathrm{CPE}_{\mathrm{dl}}$ is the double-layer capacitance. A constant phase element representing a shift from an ideal capacitor is used instead of the capacitance itself, for simplicity. The impedance of a constant phase element is defined as $Z_{\mathrm{CPE}}=\left[Q(j \omega)^{\mathrm{n}}\right]^{-1}[10 \sim 12]$, where $Q$ is a proportional factor, $\omega$ is the frequency and $-1 \leq \omega \leq 1$. The value of $n$ seems to be associated with the non-uniform distribution of current as a result of the roughness and surface defect.

It is well recognized that the polarization resistance $\left(R_{\mathrm{p}}\right)$ is inversely proportional to the corrosion rate. The $R_{\mathrm{p}}$ value is equal to the $R_{\mathrm{ct}}$ value during the first $144 \mathrm{~h}$ and the sum of the $R_{\mathrm{ct}}$ and $R_{\mathrm{pit}}$ value after $144 \mathrm{~h}$ of immersion. The $R_{\mathrm{p}}$ values obtained by analyzing impedance spectra are presented in Table 3 . The $R_{\mathrm{P}}$ values increase with the increasing corrosion time within $144 \mathrm{~h}$ of immersion, which is relates to the deposition of corrosion scales. After $144 \mathrm{~h}$, the $R_{\mathrm{P}}$ values exhibit decreasing trend, which is relate to the formation of local corrosion on sample surface. During corrosion process, the VEGW joint presents higher $\boldsymbol{R}_{\mathrm{p}}$ values than the SAW joint in $3.5 \% \mathrm{NaCl}$ solution, which complies with the $\mathrm{PC}$ results. The reason for this is associated with the welding technology. As shown in Fig 5, The SAW joint by multi-pass welding shows inferior homogeneity. As a result, the SAW joint shows 
high corrosion rate in $3.5 \% \mathrm{NaCl}$ solution.

\section{4 conclusions}

This study has performed an experimental investigation into the corrosion behaviors of welding specimens of the LCOST steel by the VEGW and the SAW in $3.5 \% \mathrm{NaCl}$ solution. The experimental findings support the following major conclusions:

(1) The VEGW joint presents coarser micro-phase and more uniform microstructure in welding zone than the SAW joint.

(2)The SVET results reveal that the VEGW joint shows small corrosion current the welding zone and the main corrosion in HAZ, while the SAW joint exhibits high corrosion current in the welding zone and the key attack in FZ.

(3) SEM results demonstrate that the VEGW joint shows alight local corrosion and the SAW joint exhibits a heavy uniform attack.

(4) Electrochemical results show that the VEGW joint shows smaller corrosion rate than the SAW joint.

(5) EIS show that the welding samples show two corrosion processes in $3.5 \% \mathrm{NaCl}$ solution. EIS shows one increasing capacitance arc in the first 144 hours due to the deposition of corrosion products, and exhibits two capacitance arcs after 144 hours owing to the formation of the local corrosion on sample surface.

(6) It can be discovered that the corrosion rate of the welding joint is associated with the welding pass, and the corrosion form of the welding sample is related to the welding heat input. 


\section{Acknowledgement}

The authors wish to thank the provincial financial support by Anhui Provincial Natural Science Foundation (1408085MKL34) and Natural Science Research Project of Anhui Province of China (KJ2016A091), This work was supported by grants from the National Natural Science Foundation of China (U1660110, 51204004)and Anhui Innovation Team Project of New Technology in Materialization of Metallurgical Solid Wastes

\section{References}

[1] Zhang YQ, Zhang HQ, Liu WM. Effects of $\mathrm{Nb}$ on microstructure and continuous cooling transformation of coarse grain heat-affected zone in 610MPa class high strength low-alloy structural steels. Mater Sci Eng: A 2009;499: ;182 186.

[2] Zhang YQ, Zhang HQ, Liu WM. Effect of heat input on the microstructure and toughness of coarse grain heat-affected zone in Nb microalloyed HSLA steels. J Iron Steel In st 2008; 16: 73 80.

[3] Ding JH, Zhang L, Lu XM. The electrochemical behavior of 316L austenitic stainless steel in $\mathrm{Cl}^{-}$containing environment under different $\mathrm{H}_{2} \mathrm{~S}$ partial pressures. Appl Surf Sci 2014; 289: 33 41.

[4] Hayashi K, Araki K, Abe T, High performance steel plates for tank and pressure vessel use -High strength Steel plates with excellent weldability and superior toughness for the energy industry. JFE Technical report 2005; 1: 66-73.

[5] Jiang LZ, Zhang HQ, Hou H. Development for a 610MPa class Q\&T high strength steel plate B610E for large oil storage tanks, J Iron Steel Inst 2007; 14: 301-305.

[6] Shinichi D, Kazuhide T, Junichi FS. Steels for production transportation and storage of energy. JFE Technical report 2004;11:55-67.

[7] Liu WM, Zhou QJ, Li LS. Effect of alloy element on corrosion behavior of the huge crude oil storage tank steel in seawater. J Alloys Compd 2014; 598:198 204.

[8] Zhang C, Cheng YF. Corrosion of Welded X100 Pipeline Steel in a Near-Neutral pH Solution. 
J Mater Eng Perform 2010; 19: 834 841.

[9] Chu F, Li XB, Zhang K,CEN F. Analysis study of hardness value distribution in welded joints by matrix method. China Measurement \& Test 2015; 41(7):28 31.

[10] Cao, CN. Principles of Electrochemistry of Corrosion, Chemical Industry Press. Beijing; 2008.

[11] Macdonald JR, Johnson WB. Impedance Spectroscopy, J Wiley and Sons, New York; 1987.

[12] Rammelt U, Reinhard G, On the applicability of a constant phase element (CPE) to the estimation of roughness of solid metal electrodes. Electrochim. Acta 1990;35:1045-1056. 
Fig 1 Schematic illustration of welded groove (a) VEGW joint (b) SAW joint Fig 2 Cross-section macro-images of both the welding technology (a) VEGW joint (b) SAW joint

Fig 3 Optical micrographs of different zones for welded joints using Vertical Electro-Gas Welding (a) base metal (b) heat effected zone (c) welded metal Fig 4 Optical micrographs of different zones for welded joints using transverse Submerged-Arc Welding (a) base metal (b) heat effected zone (c) welded metal

Fig 5 Distribution character of the hardness for both samples (a) VEGW joint

(b) SAW joint

Fig 6 SEM micrograph of samples after 144 hours immersion (a) VEGW joint

(b) SAW joint

Fig 7 SVET measurements of all weld joints in $3.5 \% \mathrm{NaCl}$ solution (a) VEGW joint (b) SAW joint

Fig 8 Polarization curves measured the sample in $3.5 \% \mathrm{NaCl}$ solution
(a) different zone of the VEGW joint (b) different zone of the SAW joint
(c) whole welded joint

Fig.9 EIS of the welding joint of the VEGW and SAW in $3.5 \% \mathrm{NaCl}$
(a)4 hours
(b) 8 hours
(c)144hours
(d) 1224hours

Fig 10 Equivalent circuits for EIS obtained in 3.5\% NaCl solution (a) former stage (b) latter stage 


\section{Fig 1 Schematic illustration of welded groove (a) VEGW joint (b) SAW joint}

Fig 2 Cross-section macro-images of both the welding technology (a) VEGW joint (b) SAW joint

Fig 3 Optical micrographs of different zones for welded joints using VEGW (a) base metal (b) heat effected zone (c) welded metal

Fig 4 Optical micrographs of different zones for welded joints using transverse Submerged-Arc Welding (a) base metal (b) heat effected zone (c) welded metal

Fig 5 Distribution character of the hardness for both samples (a) VEGW joint

(b) SAW joint

Fig 6 SEM micrograph of samples after 144 hours immersion (a) VEGW joint

(b) SAW joint

Fig 7 SVET measurements of all weld joints in 3.5\% NaCl solution (a) VEGW

joint (b) SAW joint

Fig 8 Polarization curves measured the sample in $3.5 \% \mathrm{NaCl}$ solution

(a) different zone of the VEGW joint (b) different zone of the SAW joint

(c) whole welded joint

Fig.9 EIS of the welding joint of the VEGW and SAW in $3.5 \% \mathrm{NaCl}$

(a) 4 hours (b) 8 hours (c) 144hours (d) 1224hours

Fig 10 Equivalent circuits for EIS obtained in 3.5\% NaCl solution (a) former stage

(b) latter stage 
Fig 1 Schematic illustration of welded groove (a) VEGW joint (b) SAW joint
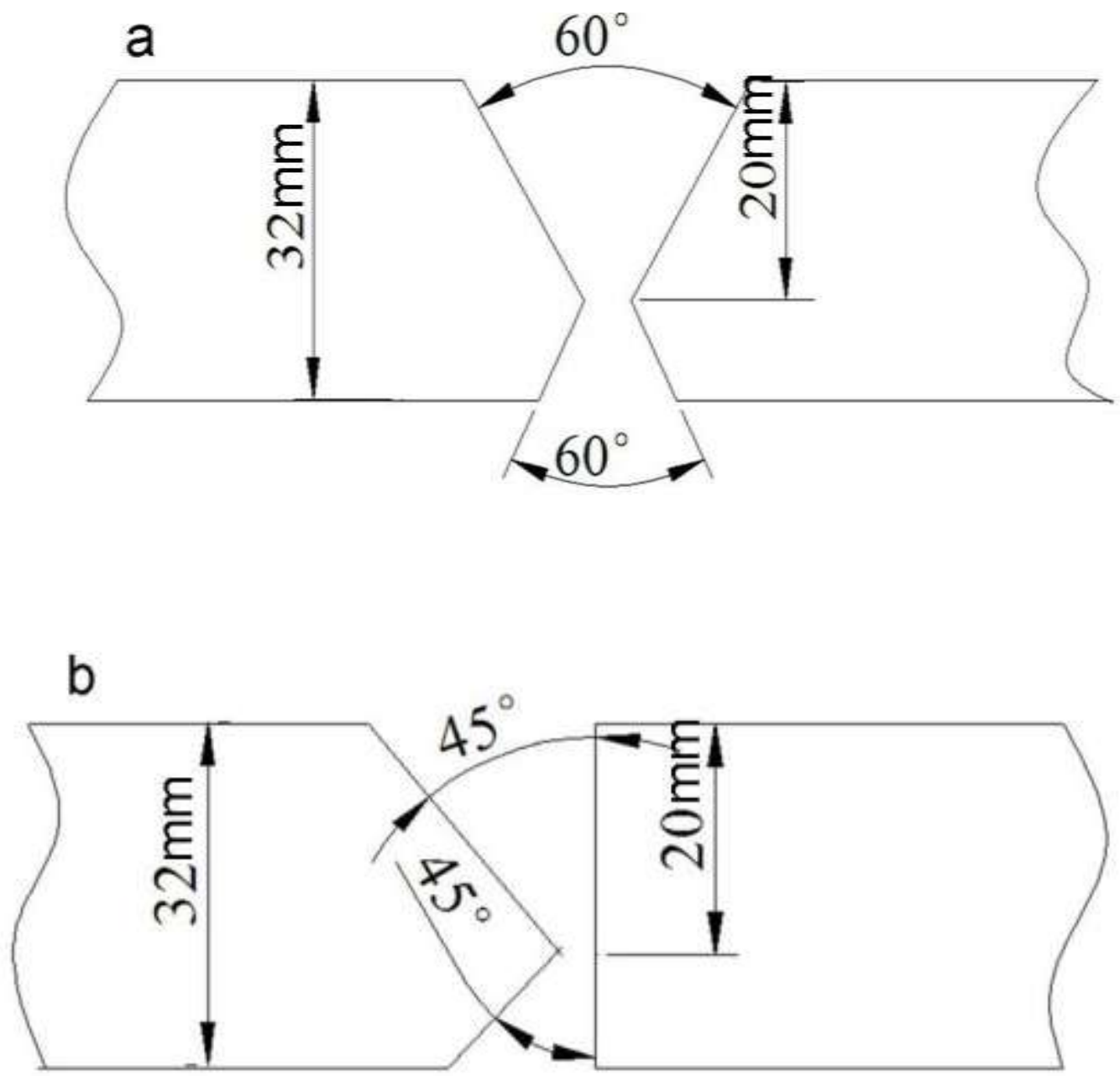
Fig 2 Cross-section macro-images of both the welding technology (a) VEGW joint

(b) SAW joint
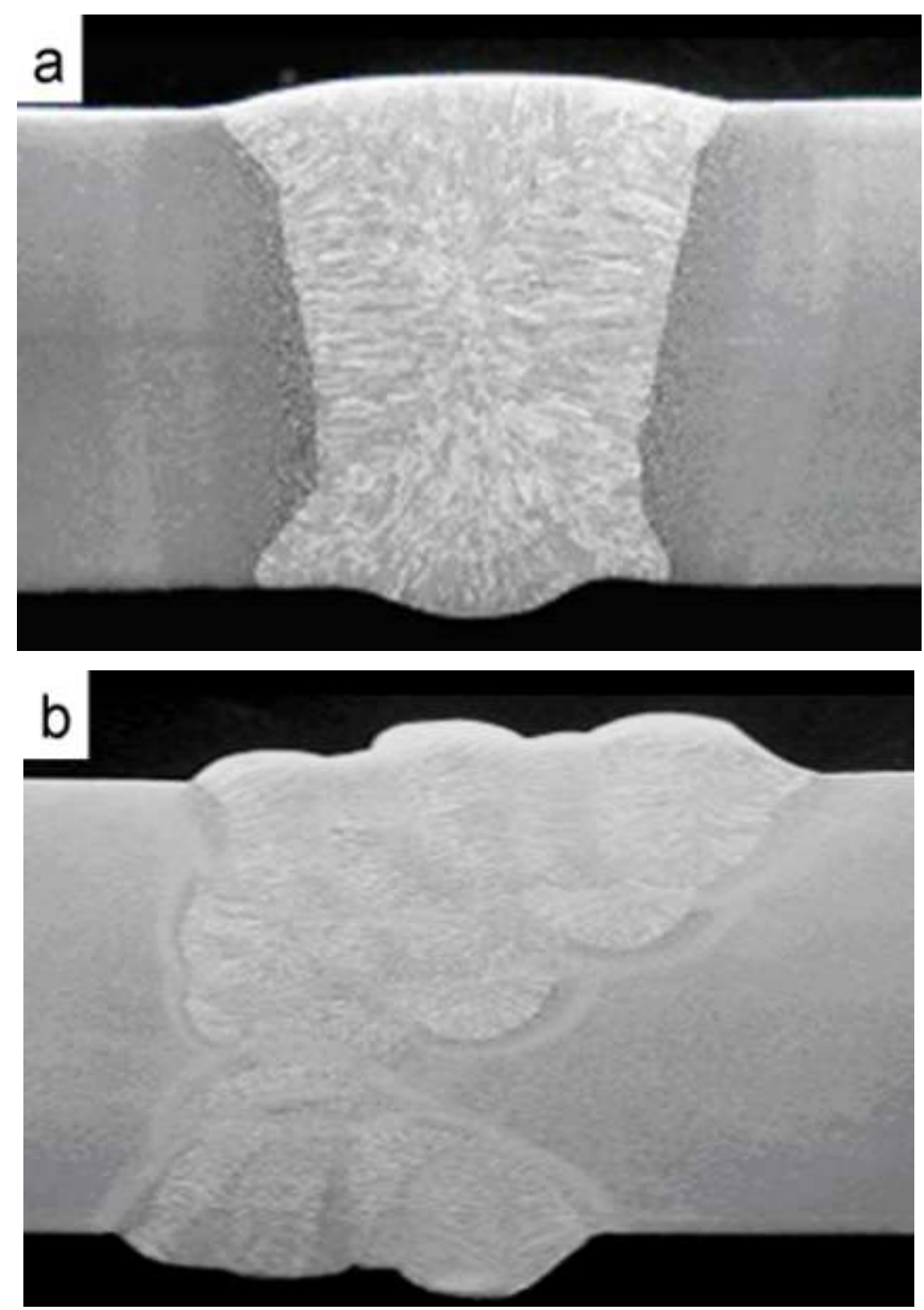
Fig 3 Fig 1 Optical micrographs of different zones for welded joints using VEGW

(a) base metal (b) heat effected zone (c) welded metal
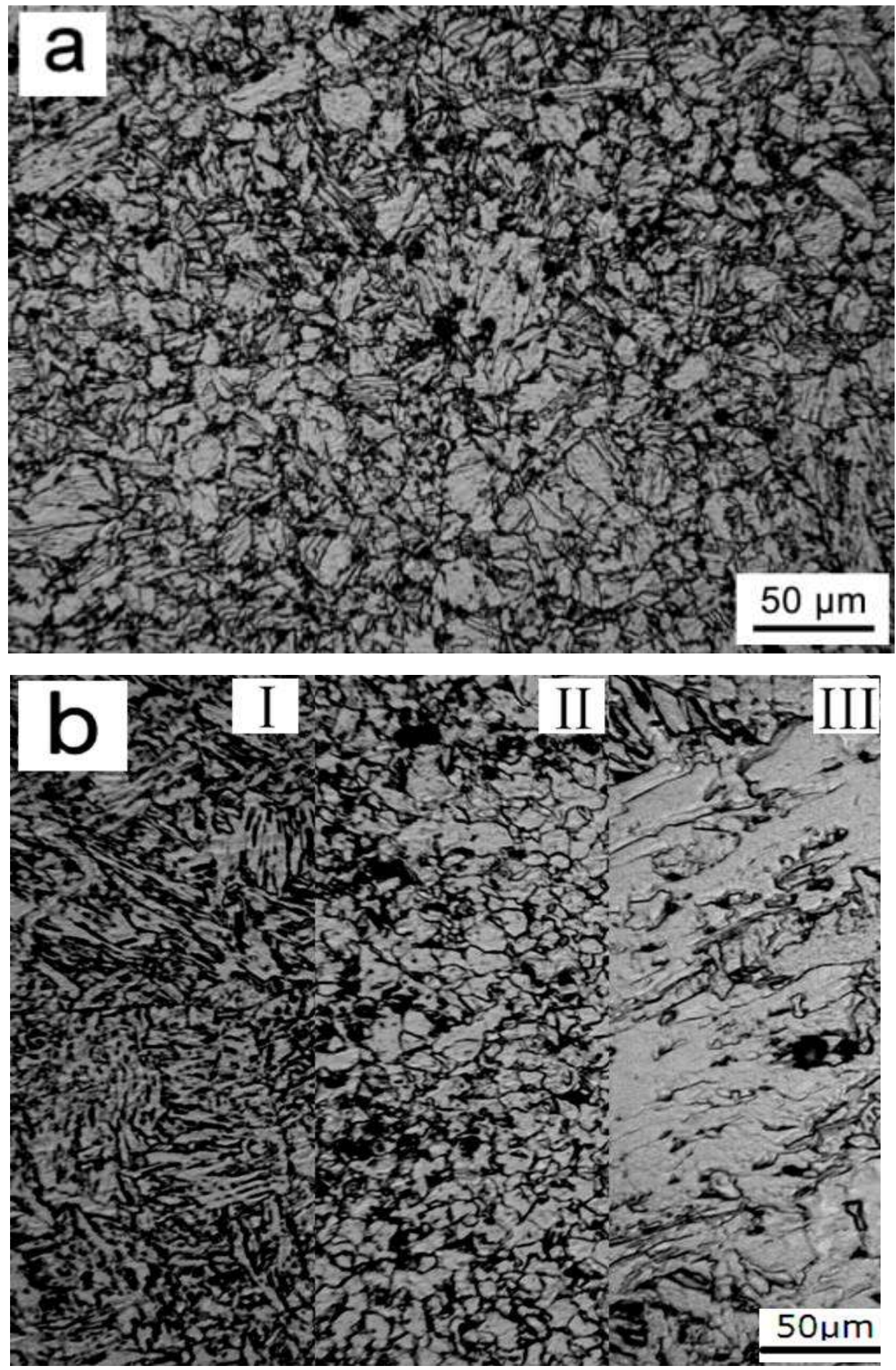


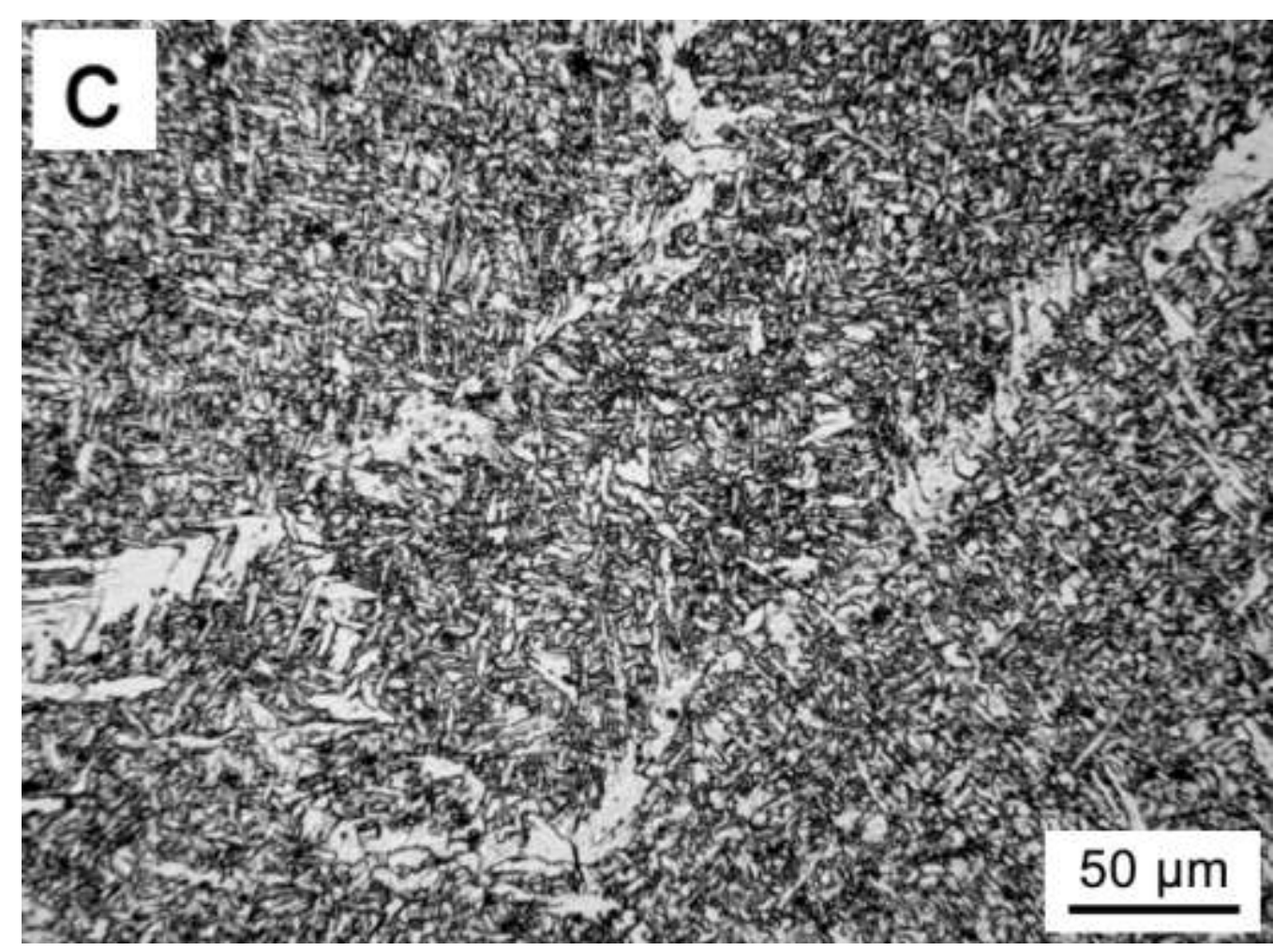


Fig 4 Optical micrographs of different zones for welded joints using transverse SAW

(a) base metal (b) heat effected zone (c) welded metal
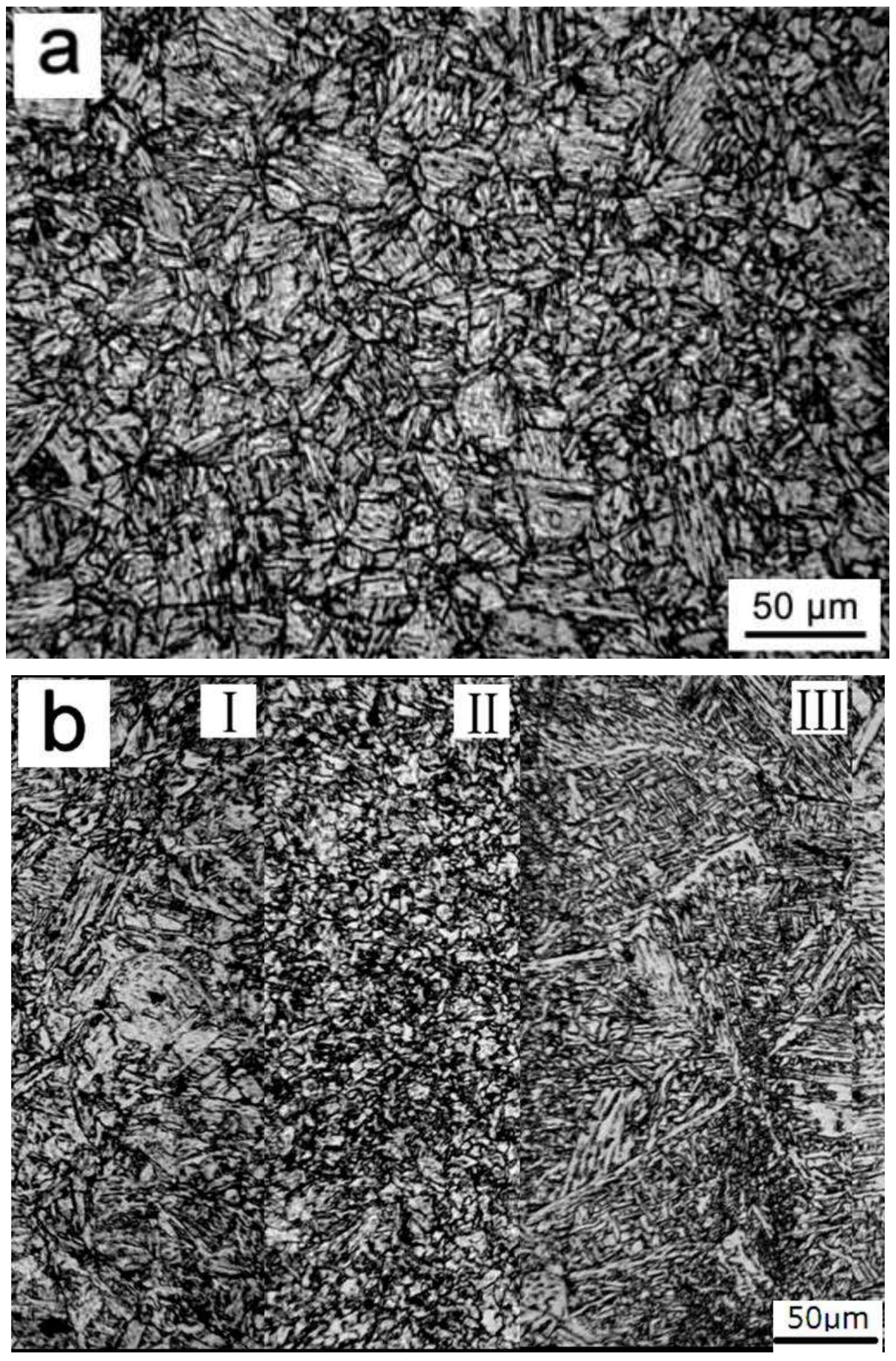


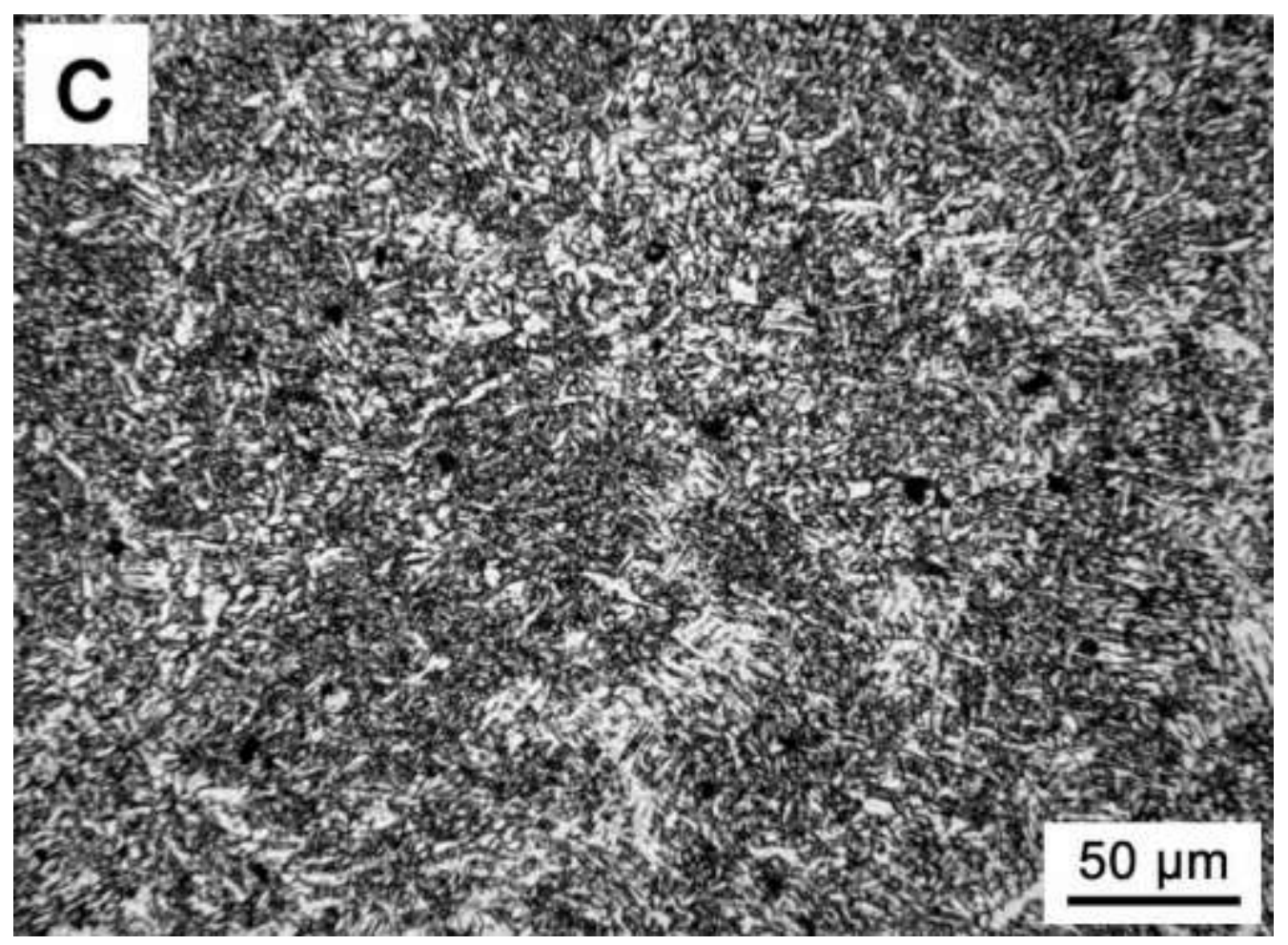


Fig 5 Distribution character of the sample hardness (a) VEGW joint $\quad$ (b) SAW joint
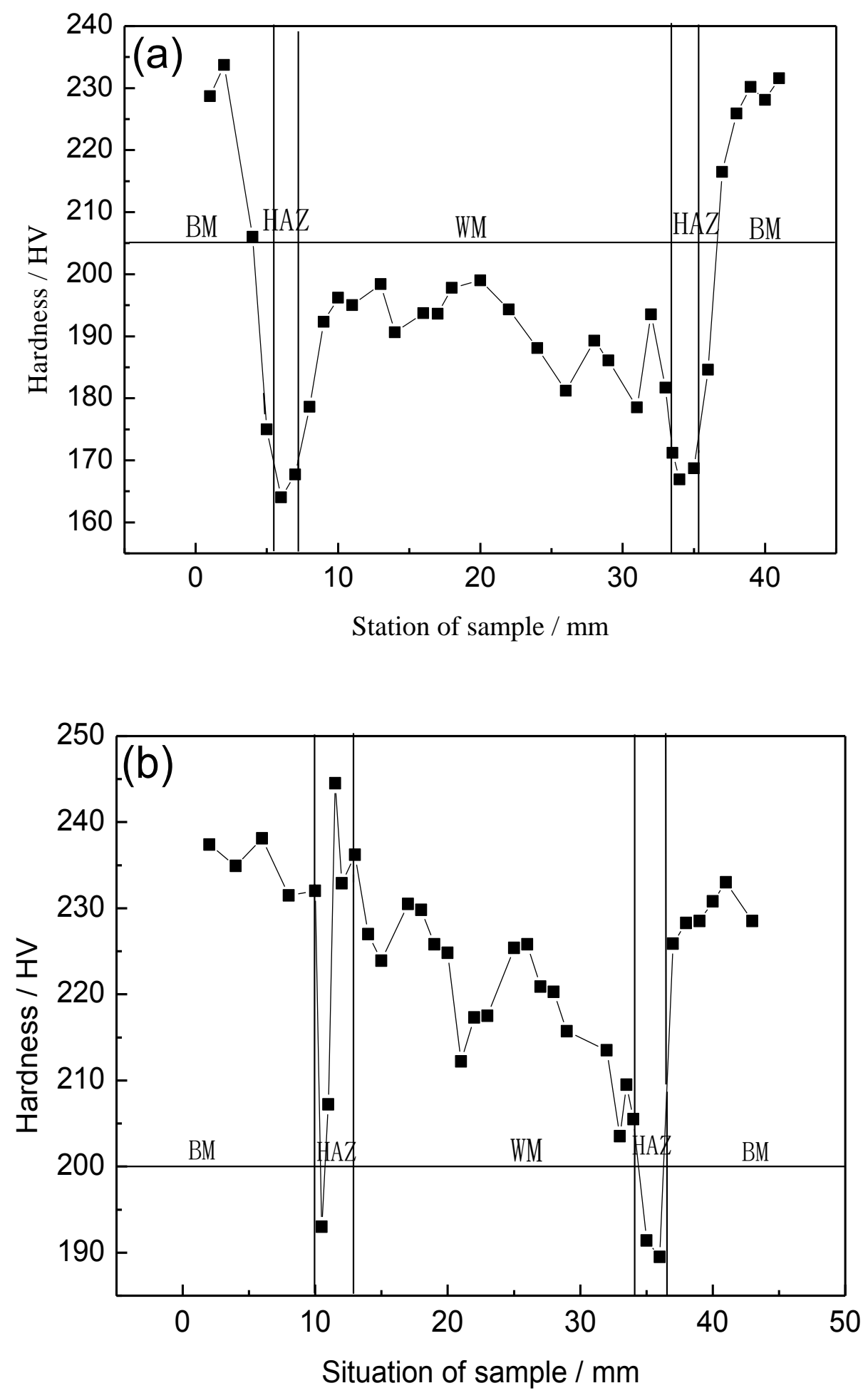
Fig 6 SEM micrograph of both samples after 144 hours immersion (a) VEGW joint (b) SAW joint
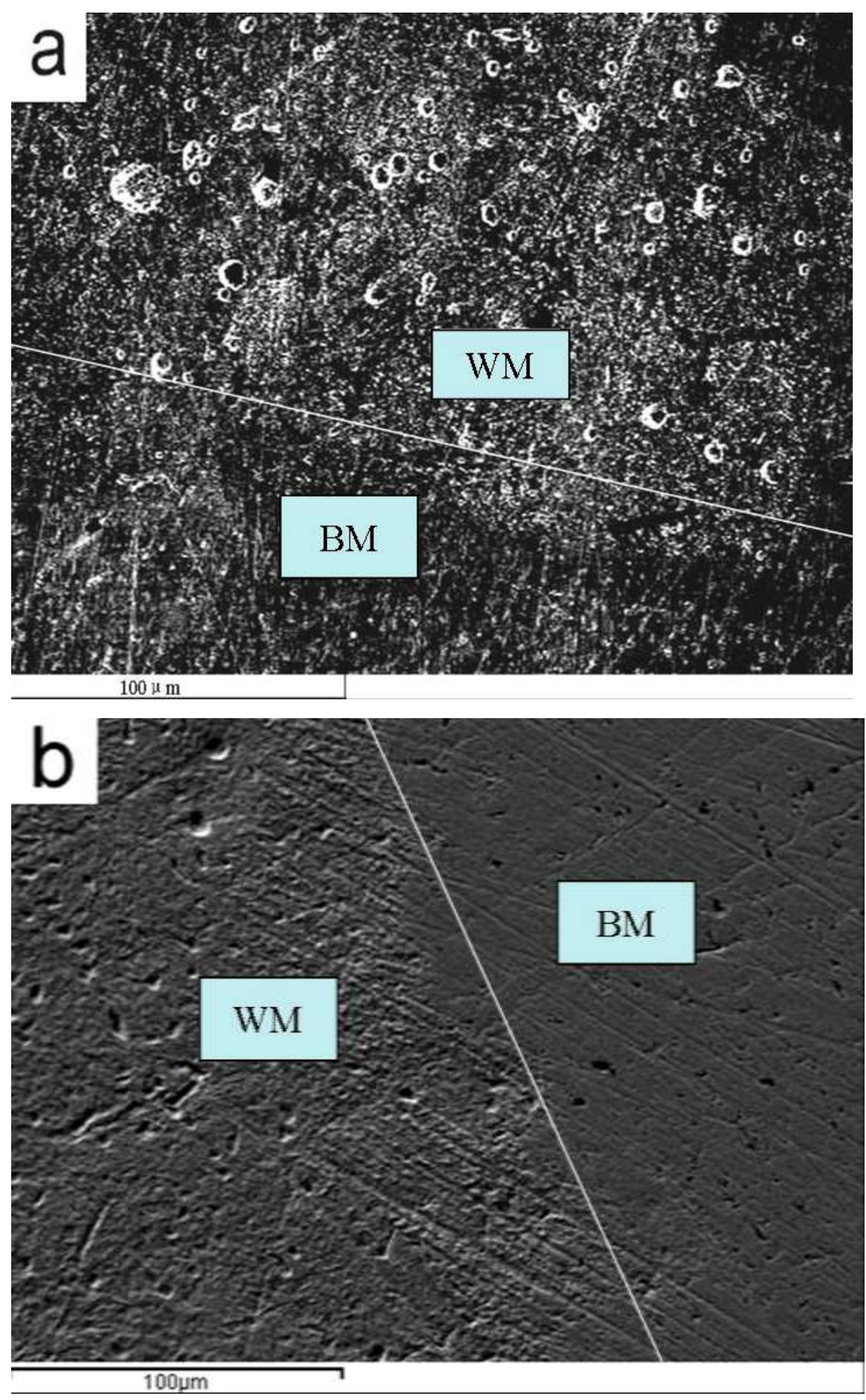
Fig 7 SVET measurements of all weld joints in $3.5 \% \mathrm{NaCl}$ solution (a) VEGW joint (b) SAW joint
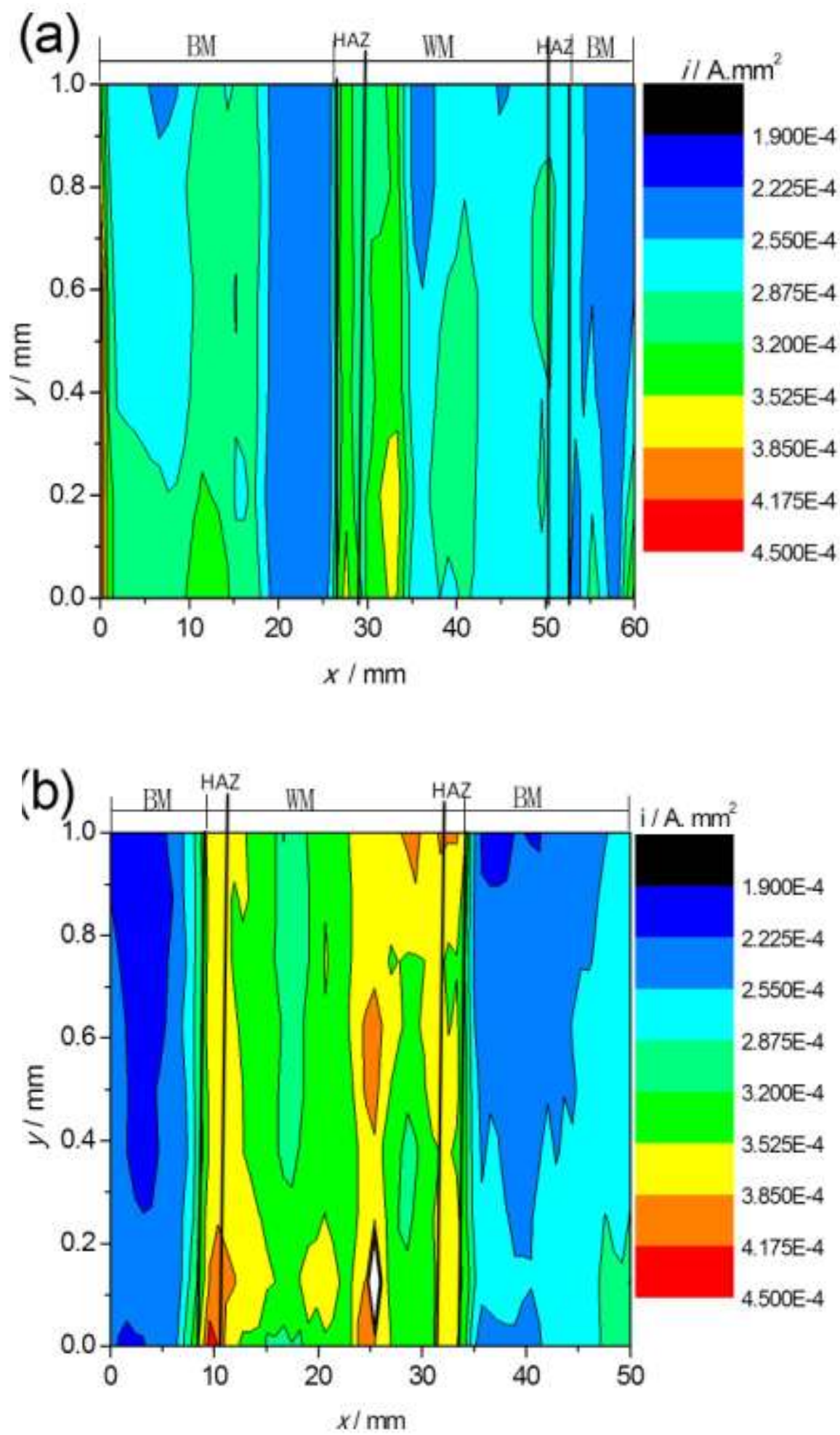
Fig 8 Polarization curves measured the sample in $3.5 \% \mathrm{NaCl}$ solution

(a) Different zone of the VEGW joint (b) different zone of the SAW joint (c) whole welded joint
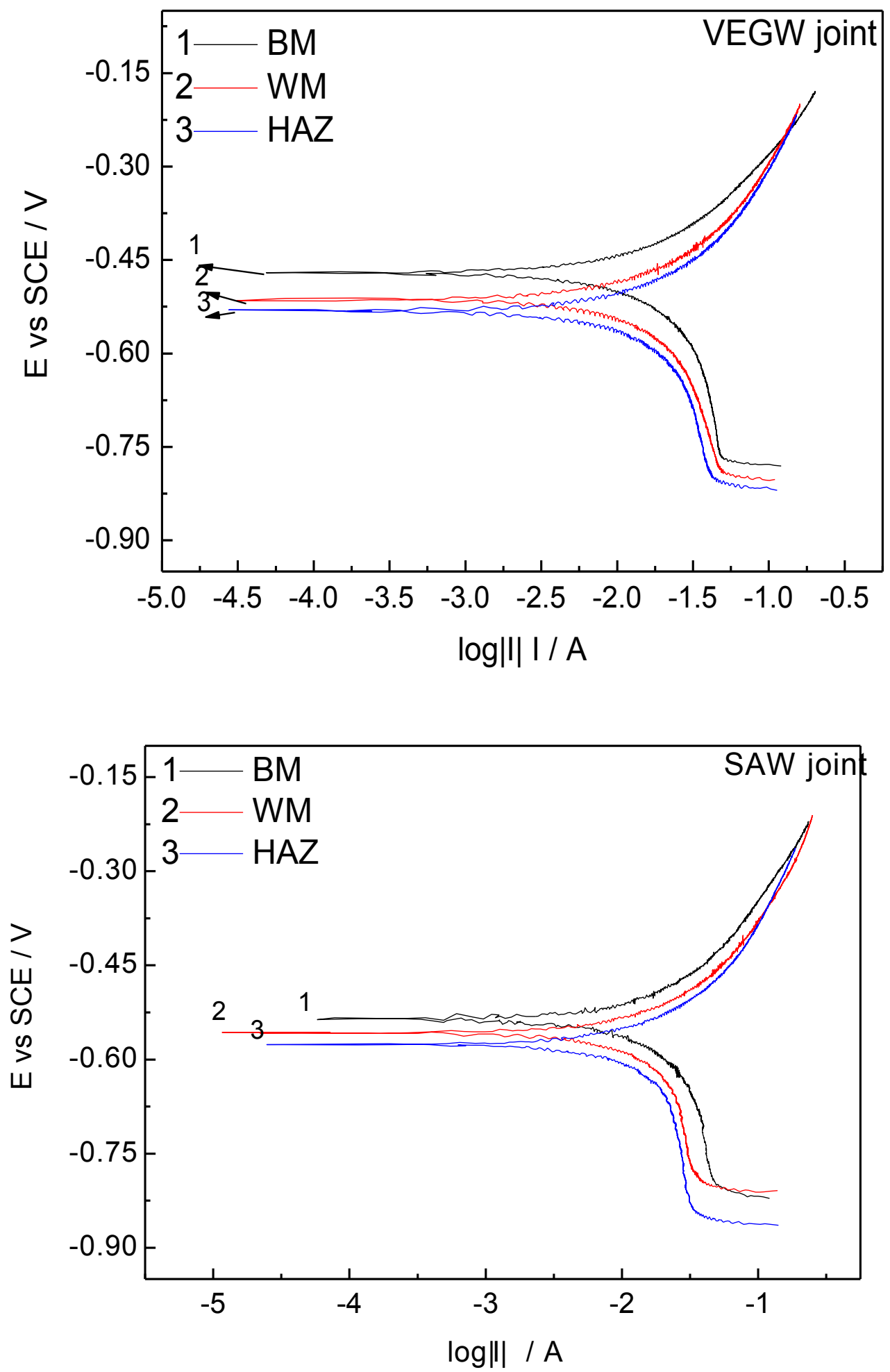


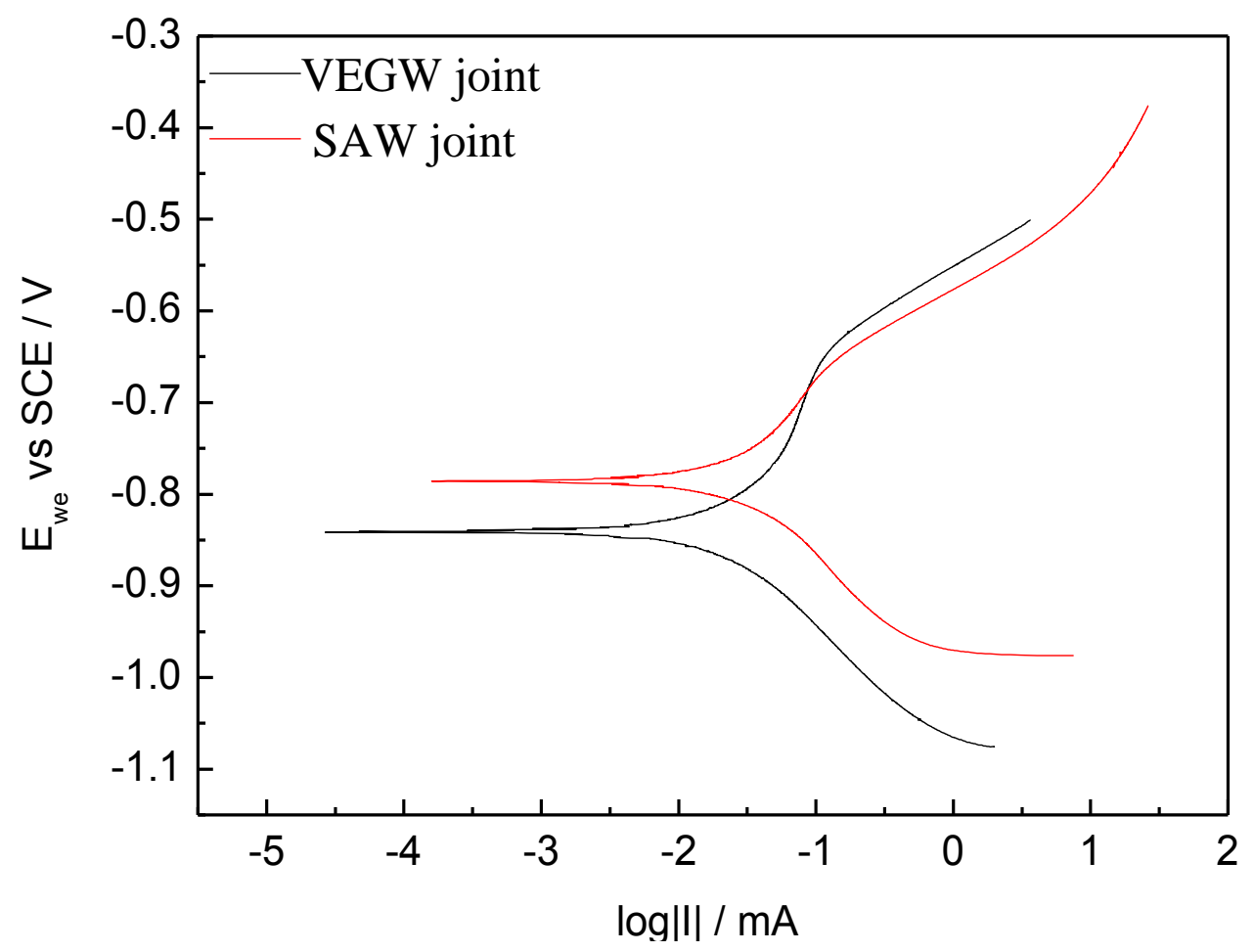


Fig.9 EIS of the welding joint of the VEGW and SAW in $3.5 \% \mathrm{NaCl}$

(a)4 hours (b) 8 hours (c)144hours (d) 1224hours
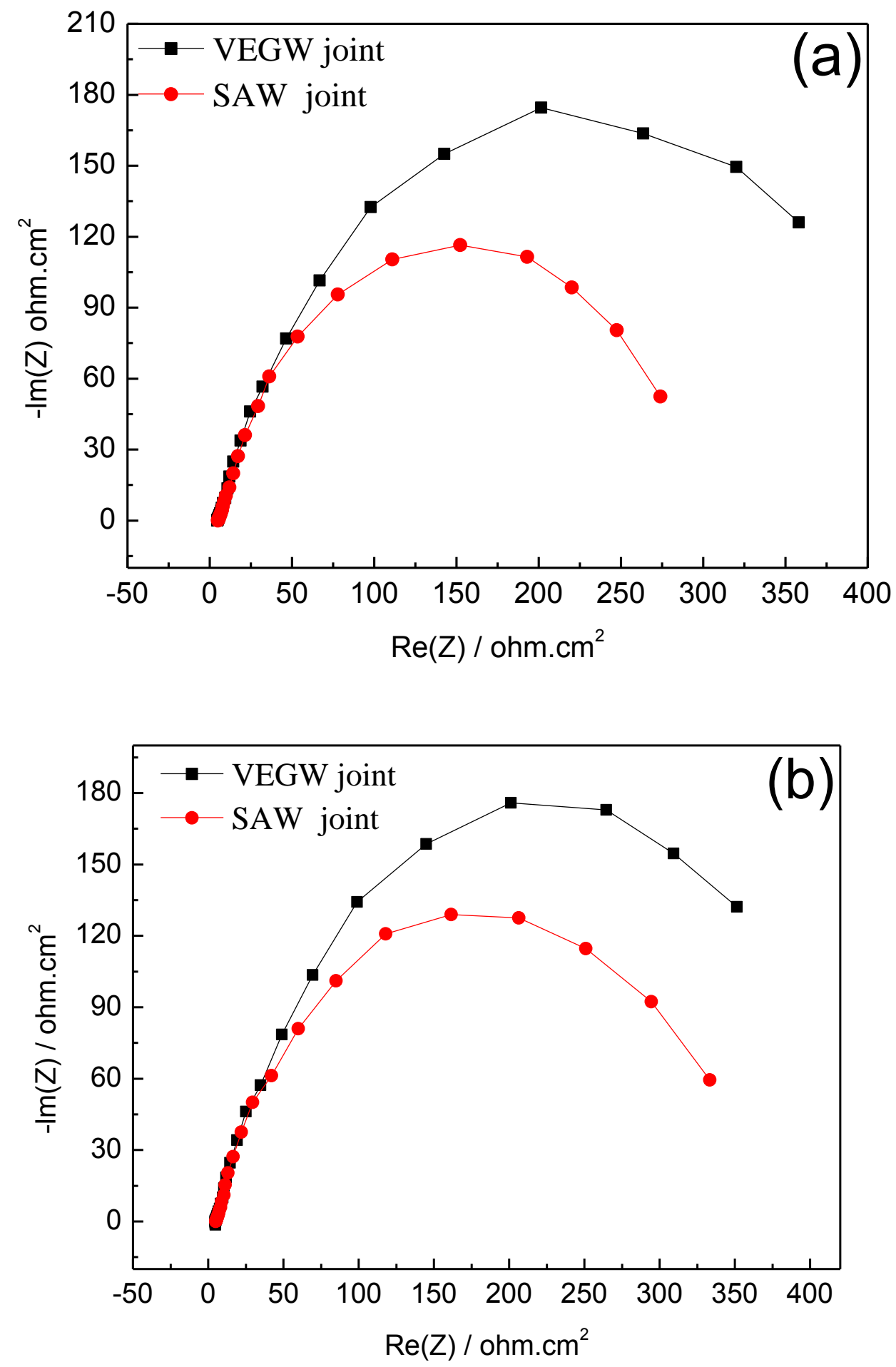

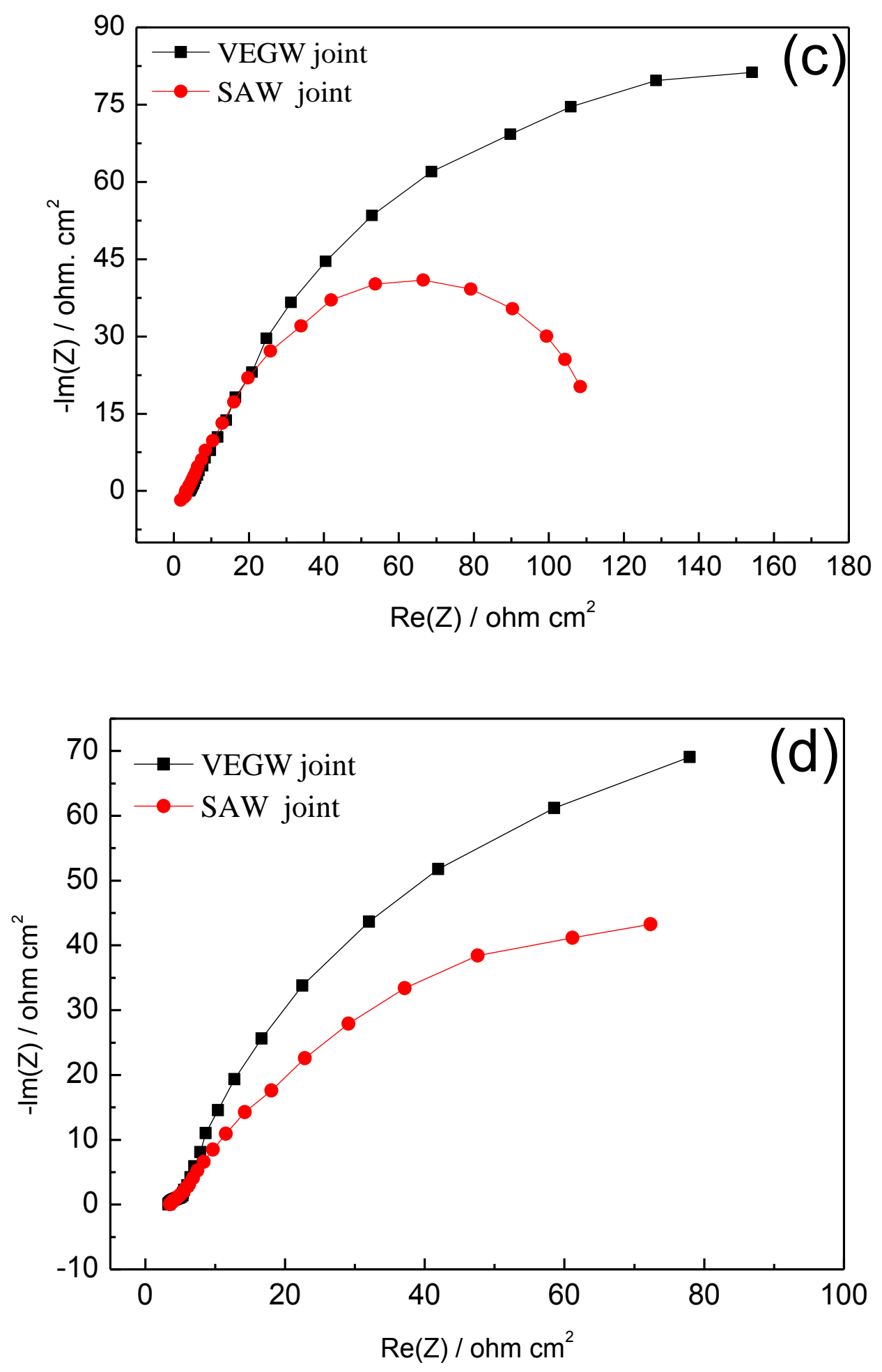
Fig 10 Equivalent circuits for EIS obtained in $3.5 \% \mathrm{NaCl}$ solution (a) former stage (b) latter stage

(a)

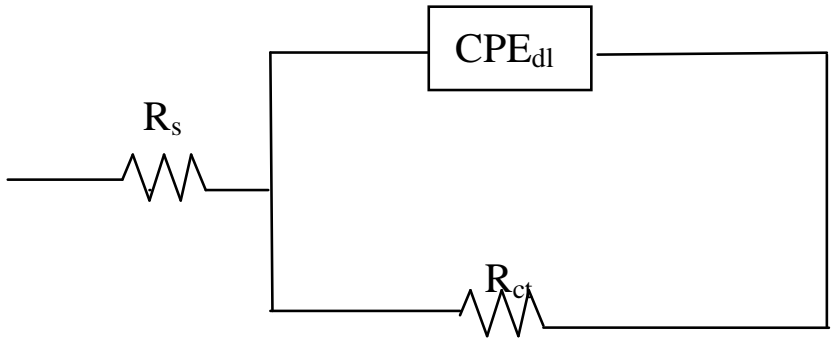

(b)

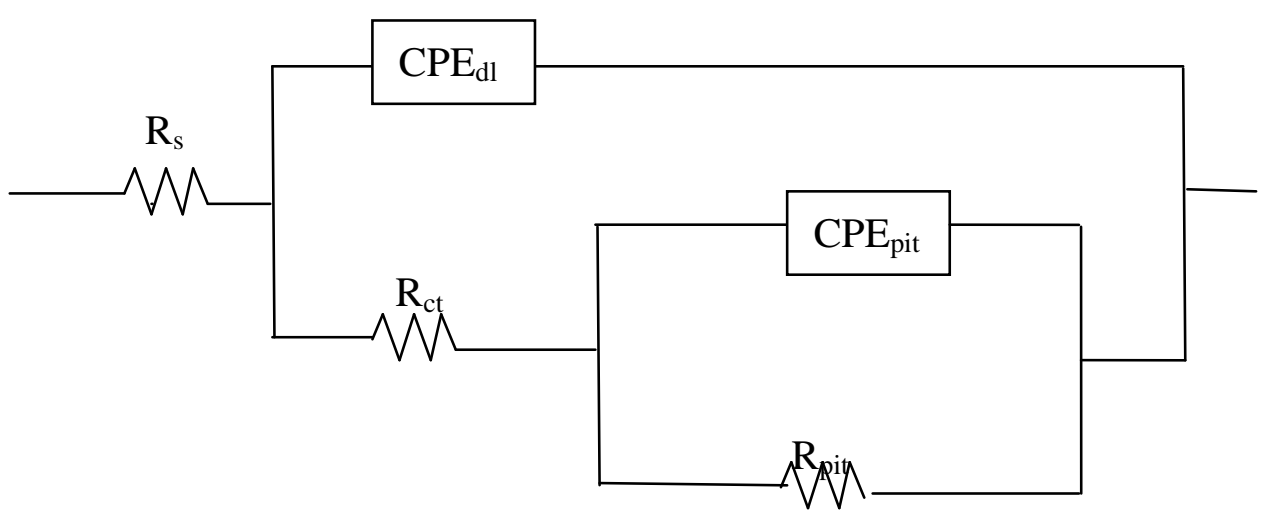


Table 1 Composition of the HSLA steel

Table 2 Fitted results to polarization curves for the sample in $3.5 \% \mathrm{NaCl}$ solution

Table 3 Parameters of fitted results with equivalent circuits for EIS at different times 
Table 1 Composition of the HSLA steel and (wt\%)

\begin{tabular}{ccccccccccccc}
\hline Material & $\mathrm{C}$ & $\mathrm{Mn}$ & $\mathrm{Si}$ & $\mathrm{Al}$ & $\mathrm{Mo}$ & $\mathrm{Cr}$ & $\mathrm{Cu}$ & $\mathrm{Nb}$ & $\mathrm{Ni}$ & $\mathrm{S}$ & $\mathrm{P}$ \\
\hline Base metal & 0.090 & 1.44 & 0.185 & 0.029 & 0.1 & 0.03 & 0.01 & 0.014 & 0.21 & 0.0015 & 0.0043 \\
SAW wire & 0.090 & 1.32 & 0.1 & 0.012 & 0.8 & 0.02 & 0.15 & 0.01 & 0.35 & 0.001 & 0.004 \\
VEGW power & 0.100 & 1.26 & 0.6 & 0.023 & 0.9 & 0.26 & 0.12 & 0.01 & 0.28 & 0.001 & 0.003 \\
\hline
\end{tabular}


Table 2 Fitted results to polarization curves for the sample in $3.5 \% \mathrm{NaCl}$ solution

\begin{tabular}{|c|c|c|c|c|c|}
\hline \multicolumn{2}{|c|}{ Sample } & \multirow{2}{*}{$\frac{E_{\text {corr }}(\mathrm{mV} \text { vs. SCE })}{-470.67}$} & \multirow{2}{*}{$\frac{I_{\text {corr }}\left(\mu \mathrm{A} \mathrm{cm}^{-2}\right)}{16.80}$} & \multirow{2}{*}{$\frac{\beta_{\mathrm{c}}\left(\mathrm{mv} \cdot \mathrm{dec}^{-1}\right)}{463.3}$} & \multirow{2}{*}{$\frac{\beta_{\mathrm{a}}\left(\mathrm{mv}^{\mathrm{dec}}{ }^{-1}\right)}{242.6}$} \\
\hline VEGW & $\mathrm{BM}$ & & & & \\
\hline & HAZ & -530.00 & 21.39 & 545.2 & 256.2 \\
\hline & WM & -513.29 & 18.77 & 476.7 & 246.2 \\
\hline & weldment & -0.841 & 22 & 155 & 214 \\
\hline \multirow[t]{4}{*}{ SAW } & $\mathrm{BM}$ & -472.20 & 17.10 & 472.2 & 235.9 \\
\hline & HAZ & 575.68 & 19.9 & 604.6 & 258.6 \\
\hline & WM & -547.16 & 23.07 & 789.1 & 227 \\
\hline & weldment & -0.786 & 36.7 & 150 & 235 \\
\hline
\end{tabular}


Table 3 Parameters of fitted results with equivalent circuits for EIS at different times

\begin{tabular}{|c|c|c|c|c|c|c|c|c|c|}
\hline $\begin{array}{l}\text { Corrosion } \\
\text { time/ h }\end{array}$ & & $\begin{array}{c}R_{\mathrm{s}} \\
/\left(\Omega \mathrm{cm}^{2}\right)\end{array}$ & $\begin{array}{c}Q_{\mathrm{dl}} \\
/\left(\Omega^{-1} \mathrm{~cm}^{-2} \mathrm{~s}^{\mathrm{n}}\right)\end{array}$ & $n_{\mathrm{dl}}$ & $\begin{array}{c}R_{\mathrm{ct}} \\
/\left(\Omega \mathrm{cm}^{2}\right)\end{array}$ & $\begin{array}{c}Q_{\mathrm{pit}} \\
/\left(\Omega^{-1} \mathrm{~cm}^{-2} \mathrm{~s}^{\mathrm{n}}\right)\end{array}$ & $N_{\text {pit }}$ & $\begin{array}{c}R_{\text {pit }} \\
/\left(\Omega \mathrm{cm}^{2}\right)\end{array}$ & $\begin{array}{c}\boldsymbol{R}_{\mathrm{p}} \\
/\left(\boldsymbol{\Omega} \mathbf{c m}^{2}\right)\end{array}$ \\
\hline \multirow[t]{2}{*}{4} & VEGW & 3.942 & $6.26 \times 10^{-3}$ & 0.78 & 378.41 & & & & 378.41 \\
\hline & SAW & 5.336 & $5.52 \times 10^{-3}$ & 0.78 & 331.22 & & & & 331.22 \\
\hline \multirow[t]{2}{*}{8} & VEGW & 3.95 & $6.94 \times 10^{-3}$ & 0.76 & 590.91 & & & & 590.91 \\
\hline & SAW & 5.37 & $5.18 \times 10^{-3}$ & 0.79 & 373.12 & & & & 373.12 \\
\hline \multirow[t]{2}{*}{144} & VEGW & 4.16 & $5.55 \times 10^{-3}$ & 0.67 & 255.91 & $7.15 \times 10^{-4}$ & 0.701 & 4.36 & 260.27 \\
\hline & SAW & 3.42 & $7.76 \times 10^{-3}$ & 0.71 & 122.49 & $5.78 \times 10^{-4}$ & 1 & 1.63 & 124.12 \\
\hline \multirow[t]{2}{*}{1224} & VEGW & 3.31 & $2.84 \times 10^{-2}$ & 0.89 & 225.68 & $1.78 \times 10^{-2}$ & 0.64 & 3.41 & 229.09 \\
\hline & SAW & 3.56 & $1.29 \times 10^{-2}$ & 0.75 & 131.42 & $1.07 \times 10^{-2}$ & 0.68 & 3.99 & 135.41 \\
\hline
\end{tabular}

